\title{
Implications for Gender Relations of Summons-Response and Address Forms in Dagbanli
}

\author{
Nantogma Alhassan Salifu (Wa, Ghana)
}

\begin{abstract}
This paper examines the structure and function of the summons and response in Dagbanli as well as address forms in the husband-wife relation. The Dagbanli language imposes different response forms on males and females and asymmetrical address terms between husband and wife. Drawing from my knowledge of the language as a native speaker and from observed practices of other speakers as well as from insights of key informants, I apply theories of sociolinguistics and pragmatics to analyze these simple conversational acts and I argue that they do not only reflect the sex differences of speakers but embed a larger gender ideology of unequal social relations between males and females in the Dagomba society.
\end{abstract}

\section{$1 \quad$ Introduction}

Dagbanli (or Dagbani) is a Gur language spoken in the Northern Region of Ghana by about 650,000 native speakers (Olawsky 1996). The people call themselves Dagbamba (sing. Dagbana), but in the literature, and among non-natives, they are referred to as Dagomba. Dagomba society is patriarchal; authority at the highest levels of the society is vested in male chiefs and at the lowest levels in male household heads.

The Dagomba value good speech behaviour, because speech is an important means by which they measure and judge a person's upbringing, character and attitude. A person who talks well is someone who is well bred. There are different norms and expectations of speech for the elderly, the young, children, women and men; and so care is taken, during the socialization process, to teach appropriate speech behaviour.

\subsection{Sex and age differences and speech behaviour among the Dagomba}

\subsubsection{Sex differences}

The Dagomba hold strong views about differences between males and females, and on the basis of these views and beliefs the Dagomba assign different roles and statuses to males and females. They believe that these differences transcend the anatomy of the body to differences in their mental abilities, their psychological state, the value of their roles in society, and even in their linguistic behavior.

For instance, the Dagomba generally hold the view that women are more talkative than men, and that much of their talk is about trivial things or about themselves and other people. In 
addition, it is a widely held view among the Dagomba that women have abrasive tongues. This view is expressed in the saying payaba mali zilima (women have tongues). The word zinli (pl. zilima) means 'tongue', but it also means 'abuse', 'ridicule', 'mockery' or 'insinuation'. Mahama (2003:288).

The claims about how much Dagomba women and men talk or what they talk about are not supported by any empirical evidence, and are not my interest in this paper. In fact, the literature shows that similar claims have been made in many other languages, but have either been found to be mere generalizations, or have been largely contradicted by empirical evidence (James and Drakich 1993). Nevertheless, there are, in Dagbanli, some linguistic forms which can empirically be shown, as I do in this paper, to be used differently by males and females. These are the summons-response forms and address forms.

\section{1. 2 Age differences}

Seniority in age, considered primarily in chronological terms, is another important marker of social differentiation and status among the Dagomba (Naden 1986). Seniority commands a lot of prestige, respect and positive self image. The elderly, and any one who is senior in age to oneself, have superior social status, and must be treated with deference, especially in verbal interaction. For example, when a younger person greets or responds to the greeting of an older person, he or she does so lowering the body and gaze, genuflecting or going down on one knee. When one approaches a group of people, he or she greets the older person(s) first before the younger ones (Naden 1986). One must respond quickly when an older person summons, and when addressing an older person, one shows deference by using an appropriate kin term or title (Salifu 2010, Dakubu 2000). The appropriate ways of addressing persons of superior social status and the elderly are taught and learnt in early childhood.

Salifu (2010) discusses these address forms as indices of politeness, power and solidarity, in the mediation of social relations. However, the implication of the choice of address forms in defining gender relations, especially between husband and wife is not addressed. In this paper I examine how Dagbanli summons and response forms, which are clearly differentiated for males and females, and address forms between husband and wife, can be viewed as linguistic enactments of gender ideology and practice that sustain a social order which is structured not only on difference but is fed by a cultural conception of the husband as socially superior to the wife.

\section{Methods of data collection}

The data for this paper was collected between 2010 and 2011as part of a broader research project on language and gender in Dagbanli. The data collection methods included observation and recordings of conversational interactions and interviews with key informants. My knowledge of Dagbanli as a native speaker and my familiarity with the norms of responding provided useful intuitive insight in the analysis. A questionnaire was also used that included a question specifically directed to married respondents on how they address 
their spouses. Their responses to this question provide the data on address forms between husbands and wives discussed in 5.1. of this paper.

\section{Theoretical perspectives}

This analysis of the male-female summons and response in Dagbanli is done in light of the Difference/Dominance approach to the study of language and gender in which differences in linguistic behavior are explained in terms of overarching social structures, of male dominance (Zimmerman and West 1975) or separate and different gendered subcultures (Maltz and Borker 1982, Tannen 1990). In this approach gender is seen as socially constructed on the foundation of sex differences through the process of socialization where gender and gendered linguistic behaviors are acquired early in life.

Gender itself needs to be distinguished from sex. Sex refers to the physiological characteristics or features by which an individual is identified as a female or a male. Gender on the other hand is the different roles and behaviors which society and culture determine as fit for each sex. Sex is a biological given; gender is learned in a social and cultural context (Wharton 2005, Doyle 1985). As a socio-culturally mediated phenomenon, gender is not static but changes over time and space.

Current Western sociolinguistic research dealing with questions of gender and sexuality has moved away from a paradigm of gender organized on binary (female-male) sex difference to one that is concerned with diversity of genders and sexual identities and practices (Cameron 2005). As Cameron notes, there has been a perceptible weakening of the most extreme forms of gender dualism and rigid gender hierarchies in Western society, and gender is no longer taken to be fixed and unalterable but is conceived as a matter of individual choice or effort (Cameron 2005:490).

In Africa however, gender may still be looked at as mapped onto biological sex differences. As Kiteku (2006) observes, in Africa differences in sex roles are perceived as "normal"; male and female roles are viewed as "different but complementary" (Kiteku 2006: 9). For instance, among the Yoruba of Nigeria, the gender construct is mediated by the philosophy of different but complementary gender roles and relations, which is rooted in the people's socio-religious experience which feeds and is fed by the belief that both male and female principles are crucial to a "smooth living experience" (Olajubu, 2002:48). In sharp contrast to the Western theory of the division of society into a domestic sphere for women and a public sphere for men, women's activities in Africa have always related to both domestic and public spheres; the African woman works both inside and outside the home doing different things that complement the man's role (Olajubu 2002).

Besides myth and popular beliefs about the linguistic behavior of males and females, there are clearly defined norms of communicative behavior for males and females in many African cultures. According to Yankah (1998, 2002), the social norms governing speaking in African cultures is not the same for males and females. Situation based control on women's speech, particularly within the public domain, appears to be widespread and may even take physical forms. For example the wearing of various types of lip plates in certain African societies whether as decoration or as instruments of speech inhibition in certain situations was a form of control applied largely to women (Yankah 1998:17). 
Also, in many of its forms, the rules of linguistic avoidance or taboo apply differently to males and females (Moshi 1985, Romaine 1999, Mbaya 2002). Romaine (1999) reports that in the Nguni culture women are expected to honor their husbands' families by avoiding the use of any word containing a syllable also contained in their husband's name, but the men are not similarly affected by the taboo. Moshi (1985) also reports that among the Zulu, women of the royal family taboo all sounds in the names of all the King's deceased forebears, lineal and collateral. Mbaya, (2002) notes that among the Oromo ethnic group of Ethiopia, a taboo prohibits wives from mentioning the birth names of their husbands, their in-laws and members of their extended families, all of who must be referred to by substituted forms (2002: 227).

In the manner of speech, Keenan (1989) reports that women and men of the Vakinankaratra people of Malagasy generally display different speech styles. It is the norm for men to be linguistically polite, avoiding open and direct expression of disagreement, disapproval or criticism in interpersonal interaction. In this society directness in speech is associated with women and children.

\subsection{The summons}

Sacks, Schegloff and Jefferson (1974) have observed that conversation is structured on a principle of speakers taking turns, and that the basic structural unit in conversation is a string of at least two turns. Some turns are more closely related than others and occur as sequenced pairs, or adjacency pairs. The production of a particular type of utterance, "a first pair part", by one speaker requires the production of a related type of utterance "a second pair part" by a second speaker; thus, a question requires an answer, a complaint an apology or justification, and a summons a response or answer (Levinson 1983, Hudson 2001). Though this principle may not occur in normal conversation across cultures, as Eckert and McConnell-Ginet (2003) have observed in some African contexts, it is noticeable in at least the summons and response sequences in Dagbanli, where a summons must obligatorily be answered.

Chaika (1982) considers summons as one of the ritualistic aspects of language, like greetings, and forms of address. It occurs regularly in conversation, and because it also serves as a starter, like greetings and address forms, summons can function as tone setters and controllers of interaction. According to Chaika:

Every interaction has to have a formal beginning. This is an indication that the hearer is supposed to start decoding a linguistic message. ... The summons grabs one's attention. ...A summons is the verbal equivalent of catching someone's eye. No conversation can proceed without one or the other. ...A summons may take many forms: Uh, Excuse me, Waiter, Joe, Dr. Dreidel. (Chaika, 1982:51-52).

The last two, as Chaika notes, are address forms and it is such forms when used as summons and the differences in response forms of males and females that I discuss in this paper.

\section{$4 \quad$ The summons as a speech act in Dagbanli}

The summons also belongs to the class of utterances which Austin (1967) described as speech acts. A speech act, according Austin, is a "statement" which when issued does not record or describe any fact but constitutes the doing or performance of an act. Such a statement or 
utterance should be analyzable into a form with a verb in the first person singular present indicative active. "Thus 'out' is equivalent to 'I declare, pronounce or call you out', 'guilty' is equivalent to 'I find you, pronounce, deem you to be guilty"' (Austin 1967: 62). Thus in Dagbanli, a summons or call, which usually constitutes no more than a vocative "Nasara", "Alasani", may, as indicated by Austin, and as will be illustrated below, be analyzable as the performative "I request, order, demand that you Nasara present yourself before me".

Austin further distinguishes three components of a speech act - locution, illocution and perlocution. Locution is the act of uttering the sound, word, phrase or sentence which constitutes the speech act, illocution is the intention of the speaker in making the utterance and perlocution is the effect of the utterance on the addressee and hearer. There are two illocutionary forces involved in a summons in Dagbanli. The speaker requires or orders the addressee to not only make a verbal response, but also to produce himself or herself before the speaker.

\subsection{The response to a summons}

The basic response to a summons or a call is $\tilde{\varepsilon} \tilde{\varepsilon}$, (uttered in a longish nasalized rising tone). It is the equivalent of the English 'yes' which a person would normally use to respond to his or her name. It is the response form used between social equals, i.e. persons of the same age or of the same social status, or by an older person when a younger person calls. When a Dagomba child begins to utter the word mma (mother) the response she or he receives from the mother is $\tilde{\varepsilon} \tilde{\varepsilon}$. This becomes the response form which young children of both sexes first learn to use when they hear their names called. For a child learning to talk, responding $\tilde{\varepsilon} \tilde{\varepsilon}$ to the mother or to any other adult is tolerated at this early age. However, from about age six, boys and girls are taught sex-differentiated response forms; nááp for boys and náá for girls. Mahama (2004) makes a note of the care taken to teach young children these different response forms:

The rudimentary training programme of a guardian includes how to respond to calls, how to receive things, eat, and how to sit down. A boy is taught to answer nááp when he is called. A girl is taught to answer náá. Both responses mean "yes" (Mahama 2004:147).

The internalization of these different forms is facilitated through the process of socialization as both sexes begin to associate more and more with their own sex groups. Once a child is considered old enough to know how to respond according to his or her sex, any further infractions are either ridiculed or met with strong disapproval.

There is no other linguistic item in Dagbanli which is so clearly differentiated for the male and the female as this. All my informants affirmed that nááp and náá are the accepted and obligatory response forms for males and females respectively. For many of them, the differences simply reflect the difference between males and females. As one female informant put it, "Male is male and female is female, and their response should be different". In other words, since the two are different, it is "natural" that they should have different responses. For one male informant "nááp is strong and náá is weak", but he could not tell exactly what he meant by "strong" or "weak"; neither could he determine what made the male form strong and 
the female form weak. One can only assume that his explanation was informed by a bias for his own male sex.

However, another informant, a traditional drummer (luya) ${ }^{1}$ provided a different but more interesting insight into the act of responding. He observed that in Dagomba practice a response is not complete until the responder presents himself or herself before the caller. A person does not only respond according to his or her sex, but also presents himself or herself to the caller and assumes a sex-appropriate posture. He explained:

When an elder calls, you do not just respond and remain sitting where you are; you move quickly to him and squat before him if you are a boy, or kneel if you are a girl.

As he made this point he assumed the different male and female postures. A boy squats with the right knee touching the floor and the left arm resting on the left thigh; a girl goes down with both knees touching the floor and the palms on the floor or on her thighs.

Note also that Mahama (2004), in the quote cited above, writes that a guardian's duty of training includes teaching the child "how to respond to calls, how to receive things, eat, and how to sit down." The response to the summons and the posture taken addressee when she or he appears before the caller are a composite act that signifies the responder's acknowledgment of his or her inferior age or status and shows deference to the caller. Dagomba etiquette requires younger persons and persons of inferior social status to squat (male) or kneel (female) when they approach or talk to superiors, or during the process of giving something to or receiving something from a superior.

This explanation goes beyond the narrow consideration of the verbalization of the response and takes into account the fuller realization of the response as a combination of a verbal and a non-verbal act. It underscores Abercombie's (1968) observation that we speak with our vocal organs but we converse with our entire bodies; i.e., in verbal interaction, non-verbal behavior is as much involved in marking relations between speaker and addressee as verbal behavior.

We noted above that as a speech act the summons in Dagbanli is an order or request for addressee to present him or herself to the summoner. When a speaker issues a summons, he or she requires two things of the addressee; response and presentation of the self. Response to a summons is obligatory; when it is omitted, its absence is acutely noticed. If the person who is summoned merely presents herself or himself to the speaker, that fact does not compensate for the breach caused by the omission of the verbal response. Merely presenting oneself without response is interpreted as sulking behavior.

To make this point clear another informant had this to say as he recalled lessons from his childhood about how his father drilled into them the inseparable routine of responding and presenting oneself:

If my father called you and you just walked up to him without first answering, he would make you walk back and respond before you proceed to him. He will instruct you to go back where you came from and respond before coming to him. He would not repeat the call, but you would just walk back, turn and utter a response, and then walk

\footnotetext{
1 The Dagomba drummers are the principal repositories of the oral traditions of the people and also instructors in etiquette (Salifu Abdulai, 2008).
} 
back to him. He would then reiterate sternly, "Be yi lan bol' a, nyin sayima." (Next time you are called, you must respond).

We see then that it is not only the verbal response which is differentiated for sex (náá for female and nááp for male). The non-verbal component of presenting oneself to the caller is also different. We may thus represent the two sex-differentiated response forms as follows:

\begin{tabular}{llll} 
Summons & $\Rightarrow$ & Response & \\
\hline Tampuli & $\Rightarrow$ & nááp + squatting & (Male respondent) \\
Nienpaga & $\Rightarrow$ & náá + kneeling & (Female respondent)
\end{tabular}

Like the verbal response, these postures are taught to the young and must be employed any time one responds when a superior calls.

\subsection{The response and social relations}

The Dagbanli response forms also mark and reflect social relations and status. The responses nááp (male) and náá (female) are used by younger persons or social inferiors when the elderly or social superiors call. Social equals and social superiors; that is, persons within the same age group or persons who consider themselves as social equals, use reciprocal $\tilde{\varepsilon} \tilde{\varepsilon}$, as noted above while persons who are separated by age or social status use non-reciprocal response forms. In the summary below I indicate reciprocity of response forms with the symbol $\Leftrightarrow$; the symbol $\neq$ indicates non-reciprocity.

1. reciprocal responses:

$\underline{\text { same age group or equal status }}$ $\tilde{\tilde{\varepsilon} \tilde{\varepsilon}} \Leftrightarrow \tilde{\varepsilon} \tilde{\varepsilon}$

2. non-reciprocal responses:

a)
social superior $\tilde{\varepsilon} \tilde{\varepsilon}$

b) husband

$\tilde{\varepsilon} \tilde{\varepsilon} \quad \neq$ younger person/

social inferior

nááp/náá

$\frac{\text { wife }}{n a ́ a ́}$

Note that among the non-reciprocal users of responses are husband and wife (2b). While a husband uses $\tilde{\varepsilon} \tilde{\varepsilon}$ as an older person or a social superior, a wife must use náá the form allowed for a younger person or a social inferior.

\subsection{Gendered aspects of Dagbanli response forms}

Gender, as a socially mediated set of behaviors, enters into the response forms in Dagbanli in a number of ways. The first is the use of non-reciprocal response forms between husband and wife as indicated above (2b) and its implication for the status of the two. Although the rules of response as indicated above apply to both females and males, the only exception is in the husband-wife relation, and this is because in Dagomba society the husband-wife relation does not accord status parity. A husband uses the response form $\tilde{\varepsilon} \tilde{\varepsilon}$, to answer his wife's call, but the wife must answer náá when the husband calls. The use of non-reciprocal responses reflects the different statuses assigned to husband and wife in a way that the Tu/Vous address forms are used in French to mark difference in status (Hudson 2001). 
Gender is also implicated in the Dagbanli summons-response form in light of further explications of the speech act theory (Austin, 1962, Searle 1975). The summons belongs to one of the categories of speech acts described as directives (Searle 1975). These are statements by which the speaker seeks to get the addressee to act in some specified way and include commands, orders, instructions, requests etc. (Searle 1975, Eckert and McConnellGinet 2003).

By the norms of culturally acceptable behavior among the Dagomba, a wife cannot order, command or give instructions to her husband. A man summons his wife and expects her to present herself before him, but a wife cannot summon her husband. "Dagban' paya ku tooi zini ka boli o yidana". (A Dagomba woman cannot sit and call (summon) her husband); that is what an elderly female informant told me. A wife must avoid explicit directives and employ what Brown and Levinson (1978) call strategies of indirection. If a woman wants to talk to her husband, she walks up to him, kneels down and politely tells him what she has to say. Where the husband is out of sight, a wife may call out his name and he will respond, and the wife will walk up to him. Neither of them will expect the husband to proceed to the wife, unless there are peculiar circumstances that make it necessary for him to do so.

Thirdly, as the individual progresses from youth into adulthood, there is a further gender differentiation in the performance of this speech act. As a man matures and advances in age he attains the superior social status accorded to all elderly men, and the number of people he will answer nááp to becomes smaller and smaller. As an adult male $\tilde{\varepsilon} \tilde{\varepsilon}$ becomes the only response form he uses. He also abandons the kneeling posture. Even when he appears before a chief at his court, he sits on the floor. For the female however there is no age limit to her use of náá; she responds náá when her husband calls, conceding to his superior status, but receives $\tilde{\varepsilon} \tilde{\varepsilon}$ from him. To her husband's relations including those of her own age she must also respond with náá. While an adult male may sit before a chief or an elder, a woman, no matter her age, must kneel when she presents herself before men.

The most revealing performance of the differentiated gender postures at any speech event is the moment when a group consisting of men and women arrive before a chief or an elder. The men assume sitting positions while all the women huddle to one side and go down on their knees bending forward with their hands on the floor, and remaining so throughout the greetings and any subsequent proceedings.

\section{$5 \quad$ Address forms in Dagbanli}

Forms of address and summons are closely linked (Chaika 1982). Both are linguistic phenomena in which social categories like status and gender, social relations like power and solidarity as well as attitudes such as politeness and deference are most manifest (Brown and Levinson 1978) The linguistic options available to a speaker of Dagbanli to address another are determined by three social variables: kin relationship, age and sex; these set up hierarchical relations between interactants that are seen as important for maintaining the social order.

Dagombas of the same age generally address or refer to one another by their given or personal names. Age differences and kinship relations between speakers however circumscribe the modes of address a speaker may use. Persons of the same age or age group address each other 
by name alone. An older person also addresses a younger person by name alone, but a younger person must not address or refer to an older person by name "without qualification" (Dakubu 2000: 63). For persons who are kin relations, the younger person uses an appropriate kin term either alone or with the name of addressee or referent. Modes of address, as Dakubu observes, are "keyed to the social hierarchy, which is viewed as an extension of the kinship hierarchy" (Dakubu 2000:64), hence in Dagbanli even older persons who are not kin relations must be addressed with a kin term.

Titles are also an obligatory element in Dagomba address practices. Besides traditional titles, titles from the Islamic religion, like Afa, Mallam, Alhaji/Hajia and English titles like $M r$. are used. Professional and occupational descriptions like "teacher", "lawyer", as well as positions like "Chairman", "Assemblyman" etc. are all used as "titles" in Dagbanli. A title confers on the holder some prestige and is therefore a valued social status marker and identity label and must be used either alone or together with a kin term to address a person who possesses it (Salifu N. A., 2010).

\subsection{Address forms between husband and wife}

Generally, norms of addressing are the same for males and females. Both must address older persons (whether relations or non-relations, male or female) using the appropriate kin terms or titles. However, as in the use of summons and responses, differences occur in the use of address forms in the context of husband-wife relations. A wife does not address or refer to her husband by name alone; she must qualify the name with a kin term or a title if he has one; e.g. $M$ be' Amadu (my elder brother Amadu). The choice of kin term is variable, but the commonest term used is beli 'elder brother', as in the above example. Even where a husband is younger than his wife, she is required to address him as 'elder brother', or else risk the social stigma of a disrespectful wife. Where a husband is much older, as may often be the case where a man can marry a woman as young as some of his senior children, the wife may address him as 'father'. A husband, on the other hand, addresses his wife by name only just as a superior in age or status addresses and inferior.

As indicated earlier, during the main research project, married respondents were asked to indicate how they address or refer to their spouses, and 85 persons responded to this question. This was made up of 36 husbands and 49 wives. Eleven of the men had two wives each, one man had three wives and the rest (14) had one wife each. All the 36 husbands address or refer to their wives by name alone; for example, Adisa, Awabu, Fati; some use familiarizing diminutives like Muni (for Muniratu), Sala (Salamatu), Anda (Andaratu). One husband, who has two wives, addresses and refers to his second wife with the diminutive Rabi (for Rabiatu), but uses the title Hajia to address the senior wife who has made the Muslim pilgrimage to Mecca. This is not an exception or a breach of the norm, but a confirmation of the obligatory use of titles. Before the wife went on the pilgrimage the husband addressed her with the given name, Adamu, but the moment she returned from Mecca, she became Hajia to everyone because failure to use the title, even by the husband, will be interpreted as indifference to her new prestigious status. 
On the other hand, none of the 49 wives addresses or refers to her husband by name only. They use kin terms or titles.

3. Kin term + Name $(\mathrm{Kt}+\mathrm{N})-M b a+A m a d u$ : Mba Amadu (my father Amadu)

- Mbe + Sule: Mbe Sule (my elder brother Sule)

4. Title + Name $(\mathrm{T}+\mathrm{N}) \quad-A f a+$ Issa: Afa Issa

$-M r+$ Yahaya: Mr. Yahaya

5. Title without Name $(T+\varnothing)$ - Alhaji

- Chief

The use of a particular term of address may vary depending on variables like location and level of education of respondents. In a typically rural community where the level of education is low, one may hear less of such terms as Mr., Chief, Master ${ }^{2}$. These are used more by wives to their educated husbands, mostly in the urban communities. The table below shows the terms of address used by the 49 women to their husbands.

\begin{tabular}{|c|c|}
\hline Address form & $\begin{array}{c}\text { Number of } \\
\text { wives }\end{array}$ \\
\hline $\mathbf{K t}+\mathbf{N}$ & 15 \\
$\mathbf{T}+\mathbf{N}:$ & 9 \\
i. $M r+N$ & 7 \\
ii. Afa $+N$ & \\
$\mathbf{T}+\boldsymbol{\emptyset : ~}$ & 4 \\
i. Alhaji & 1 \\
ii. Chief & 2 \\
iii. Master & 2 \\
iv. Teacher & 1 \\
v. Assemblyman & 1 \\
vi. Chairman & 7 \\
vii. other titles $*$ & $\mathbf{4 9}$ \\
\hline
\end{tabular}

*Traditional Dagomba titles.

The husbands indicated that they use the same form (name only) whether in face-to-face interaction with their wives or in conversation with others, but the wives indicated that in conversation with other women they sometimes refer to their husbands in slightly nonformalized ways. A woman may refer to her husband as "father of $X^{\prime}$, using the name of one of her children, usually the first born or the last born, e.g. Balchisu ba [Balchisu father] "Balchisu's father" or some other reference.

$N$ yi yen boli $n$ yidana, $n$ yeri mi mbe Issa, amaa m mini $n$ paya taba yi zia ni to bolo n duulana,"

"When I am going to call my husband, I say 'mbe Issa', but when I am with my women friends I can call him " $n$ duu lana".

Mbe Issa means 'my elder brother Issa', and ' $N$ duu lana' is 'my room owner', the owner of my room.

2 'Master' here refers to school master. When teachers rise to the position of Head teacher or headmaster, they become simply 'Master' to everyone including their wives. 


\subsection{The superior social status of the husband}

The non-reciprocal address form between husband and wife is informed by the Dagomba view of the husband-wife relation as one of an unequal relationship: a superior-inferior, super ordinate-subordinate relationship. There are several dimensions and conceptions of this inequality; the foremost being that the husband is the "senior" and the social superior. A female informant put it thus,

Paya yun kuli mi la o yidan’ n nye kpema ni yuna, di zuyu o booni o la o beli. Dagbamba yerimi ni paya bi kpem doo.

(A wife indeed knows that her husband is senior to her, so she calls him her senior brother. The Dagomba say that a woman is not older than a man.)

That a wife is "not older" than (or senior to) her husband is a principle that governs most male-female relations among the Dagomba and a fundamental code in Dagomba marriage. A wife may be chronologically older than her husband, but socially she is regarded as the "younger". It is an ideology that is reflected and reinforced in many cultural practices, including the husband-wife response forms already discussed above, and in address forms used by husband and wife. An educationist and social worker had this to say on the husbandwife address forms:

Men call their wives by their name. Women call their husbands by adding "mbeli" e.g. Mbeli Adam - my senior brother Adam. Even when a wife is older than the husband she still considers him as a senior brother. This is a degree of politeness. Sometimes they can say Afa Adam. When the husband has the same name as the wife's father some women call the husband father...my wife calls me Mr. Yahaya, sometimes Daddy.

The use of 'Daddy', or 'Dada' and 'Mama' is common among Ghanaians with Western education.

Mbaya (2002) and Akinbiyi (2010) describe similar husband-wife relationships and address forms used by wives among the Oromo of Ethiopia and Yoruba of Nigeria respectively. Among the Oromo a woman avoids mentioning the name of a husband and may refer to him as "father of $x$ " using the name of a male child (Mbaya 2002:228), and according to Akinbiyi, Yoruba women are expected, by socialization to defer to their husbands who are considered their social superiors.

Duranti and Goodwin (1992) have observed that certain linguistic features index or point to more than one dimension of the socio-cultural context; "indexing of certain dimensions is linked in a constitutive sense to the indexing of other dimensions" (Duranti and Goodwin, 1992:335). Kin relationships set up different types of rights, obligations and privileges for kinsfolk. Each relationship term evokes certain feelings, expectations, rights and duties, hopes and fears associated with the particular relationship; the reiteration of kin relations through $\mathrm{Kt}$ address forms reminds speaker and addressee of the ties and obligations that hold between them as kin, and strengthens those relations (Lydall 1999). 
Kt's index solidarity between kinsfolk and strengthen the sense of mutual obligations, duties and rights (Schusky 1974); at the same time they signify the power of the superior kin and establish a degree of social distance. As Oppong (1973) observes, not even sibling relations make a younger sibling equal to an older sibling and the former must use the kin term mbeli when addressing an older sibling and concede precedence to him or her. Therefore through the obligatory use of a superior kin term beli (elder brother), ba (father) a wife acknowledges the social distance that exists between her and her husband and concedes precedence to him.

A wife uses a Kt to address her husband to show respect to him or to attend to his positive face (Levinson 1983; Brown and Levinson 1987). She acknowledges the husband's superior social status, his power and his right to the privileges of a social superior. Conversely, when a husband uses name only to address his wife he is asserting his superior status and making a claim to power over her.

\section{Conclusion}

I have shown that in Dagbanli, the response to summons is clearly sex-differentiated, and that while the male form changes as a speaker gains superior status both as an adult and as a husband, the response and posture of the female remain unchanged by age or marital status. In the company of adult males she must use the inferior response form and in the context of marriage she is the inferior partner as reflected by her response to her husband. Thus the response, whether considered on its own or together with the summons reflects the Dagomba conception of the male and female as different and the male, especially in the husband-wife relation, as the superior.

The two speech acts also reflect and reproduce a gender relationship of male dominance. A woman must not be seen even in speech to be imposing herself on the husband. The avoidance of summoning a husband and the use of kin terms to address him both indicate a woman's acknowledgment of the man's power. These instances of linguistic behaviour underscores the point that in Dagomba society where the hold of tradition and patriarchy still remains very strong sex differences are still relevant in discussing language and gender. Arguments that gender need no longer be seen in terms of binary sex differences needs to be applied with caution in African contexts.

\section{References}

Abercombie, David (1968): "Paralanguage". British Journal of Disorders of Communication 3: $55-59$.

Akinbiyi, Adetunji (2010): "Aspects of Linguistic Violence to Nigerian Women". Language, Society and Culture 31: 10-17

Austin, John L. (1962): How to Do Things with Words. Cambridge, MA: Harvard University Press.

Blench, Roger et al. (2004): Dagbani-English Dictionary (Circulation Draft 2004). www.rogerblench.info/Language/Niger-Congo/Gur/Dagbani\%20dictionary\%20CD.pdf, accessed January 21, 2014.

Brown, Penelope/Levinson, Stephen (1978): Politeness: Some universals in language usage. Cambridge:

Cambridge University Press. 
Cameron, Deborah (2005): "Language, Gender and Sexuality: Current Issues and New Directions". Applied Linguistics 26/4: 482-502.

Chaika, Elaine (1982): Language. The social mirror. Rowley: Newbury House Publishing.

Dakubu, Mary E. K. (2000): "Personal Names of the Dagomba". Research Review. New Series 16/2: 53-65.

Doyle, James A. (1985): Sex and Gender. Philadelphia: Wm C. Brown Publishers.

Duranti, Antonio/Goodwin, Charles (1992): Rethinking context: Language as an interactive phenomenon. Cambridge: Cambridge University Press.

Eckert, Penelope/McConnell-Ginet, Sally (2003): Language and Gender. Cambridge: Cambridge University Press.

Hudson, Richard A. (2001): Sociolinguistics. Cambridge: Cambridge University Press.

James, Deborah/Drakich, Janice (1993): "Understanding gender differences in amount of talk: a critical review of research". In: Tannen, Deborah (ed.) (1993): Gender and conversational interaction. New York, Oxford University Press: 281-312.

Keenan, Elinor (1989): "Norm-makers, Norm-breakers: Uses of speech by men and women in a Malagasy community". In: Bauman, Richard/Sherzer, Joel: Explorations in the ethnography of speaking. Cambridge, Cambridge University Press: 125-143.

Kiteku, Catherine W. (2006): "Which Way Forward? Gender Theories, Debates and Practice after the Nairobi and Beijing Conferences". CODESRIA Bulletin 1 \& 2/2006: 8-9.

Levinson, Stephen C. (1983): Pragmatics. Cambridge: Cambridge University Press.

Lydall, Jean (1999): "The appealing use of Terms of Address among the Hamar in Southern Ethiopia". Paper presented at the seminar on Social interaction and language use in Africa. Afrika Studie centrum, Leiden, 28 October 1999.

Mahama, Ibrahim (2003): Dagbani-English Dictionary. Tamale: GILLBT.

Mahama, Ibrahim (2004): History and Traditions of Dagbon. Tamale: GILLBT.

Maltz, Daniel N./Borker, Ruth A. (1982): "A cultural approach to male-female miscommunication." In: Gumperz, John J. (ed.): Language and Social Identity, Cambridge, Cambridge University Press: 196-216

Mbaya, Maweja (2002): "Linguistic Taboo in African Marriage Context: A Study of the Oromo Laguu". Nordic Journal of African Studies 11/2: 224-235.

Moshi, Lioba (1985): The Manifestation of Gender in Some African Languages. www.uga.edu/womanist/moshi2.1.htm, accessed February 21, 2010.

Naden, T. (1986): "Social Context and Mampruli Greetings". In: Huttar, George/Gregerson, Kenneth (eds.): Pragmatics in Non-Western Perspective. Dallas: SIL/UTA. (SIL Publications in Linguistics 73): 161-199

Olajubu, Oyeronke (2002): "Seeing Through a Woman's Eye: Yoruba Religious Tradition and Gender Relations". Journal of Feminist Studies in Religion 3/22: 41-60.

Olawsky, Knut J. (1996): An introduction to Dagbani Phonology. Düsseldorf: Heinrich Heine Universität. (=Arbeiten des $S F B 28276$ )

Oppong, Christine (1973): Growing up in Dagbon. Accra: Ghana Publishing Corporation.

Romaine, Suzanne (1999): Communicating Gender. Mahwah NJ: Lawrence Erlbaum.

Sacks, Harvey/Schegloff Emanuel/Jefferson, Gail (1974): "A simplest systematic for the organization of turn-taking for conversation". Language 50/4: 696-735.

Salifu, Abdulai (2008): Names that prick: Royal praise names in Dagbon, Northern Ghana. Michigan: ProQuest. 
Salifu Nantogma Alhassan (2010): "Signaling Politeness, Power and Solidarity through Terms of Address in Dagbanli". Nordic Journal of African Studies 19/4: 274-292.

Schusky, Ernest L. (1974): Variation in Kinship. New York: Holt, Rinehart and Winston.

Searle John (1975): "Indirect speech acts". In: Cole, Peter/Morgan, Jerry (eds): Syntax and Semantics, Vol. 3: Speech Act. New York, Academic Press: 59-82

Tannen, Deborah (ed.) (1990): You Just Don't Understand. New York. Oxford University Press.

Wharton, Amy S. (2005): The Sociology of Gender. Malden MA: Blackwell Publishing.

Yankah, Kwesi (1998): Free Speech in Traditional African Society: The Cultural Foundations of Communication in Contemporary Ghana. Accra: Ghana Universities Press. Yankah, Kwesi (2002): "Free Speech as Therapeutic Discourse: An Ethnography". In: Ameka, Felix/Osam, E. Kweku (eds.): New Directions in Ghanaian Linguistics. Accra, Black Mask: 426-447.

Zimmerman, Don H./West, Candace (1975): "Sex roles, Interruptions and Silences in Conversation". In: Thorne, Barry/Henley, Nancy (eds.): Language and Sex: Difference and Dominance. Rowley MA, Newbury House: 105-129. 